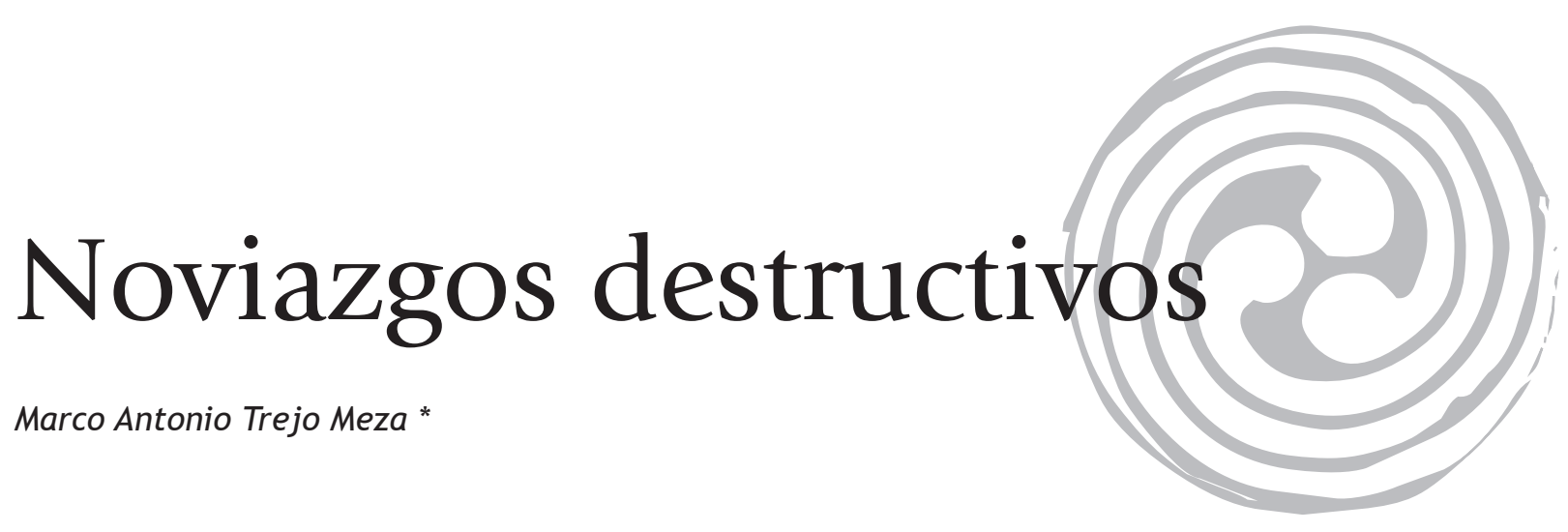

RESUMEN

El presente trabajo analiza, cómo el noviazgo entre sus aristas, existe una que no es placentera, los noviazgos destructivos, así pues muestra cómo se ha vivido a través de la historia y cómo se llega a destruir una relación, los factores que surgen, llevando a las personas a tener una vida infeliz, en algunos casos, otros mas dramáticos son los que sobreviven el noviazgo, llegando al matrimonio. Lo cierto es que este hecho se manifiesta como un problema social.

\section{Introducción o@}

El noviazgo ha sido siempre un tema central en la vida de muchas personas, los noviazgos tendrán varias etapas, entre ellas existe una que puede ser más significativa, la que se da al final de la adolescencia o principio de la juventud. Toma otro relieve por la circunstancia que va acompañando a este a acontecimiento, es decir la elección de carrera. Pensar profundamente cómo y con quién se compartirá la vida, (Ericsson, 1976) etapa en la cual se estará en crisis, pues es mucho lo que está en juego, lo interesante de este trabajo es conocer la estructura que se construye para tener un noviazgo destructivo.

\section{Problema de investigación}

Se elige este tema de investigación por los hechos cotidianos y frecuentes con los que se manifiestan los noviazgos destructivos, sin importar la condición sociocultural, económica o religiosa. Los cuales se manifestarán o tendrán impacto en la sociedad.

\section{Preguntas de investigación}

¿Cómo en los distintos tipos de noviazgo que se practican, se llega a un noviazgo destructivo? ¿Qué factores son comunes?

\footnotetext{
* Estudiante de cuarto semestre de Psicología

¿Por qué algunas de las partes permite la relación destructiva?

\section{Objetivo general.}

Identificar las causas psicológicas y socioculturales que originan un noviazgo destructivo, a través de instrumentos de entrevistas semiestructuradas e historias de vida, a estudiantes de la universidad La Salle, Universidad del estado de Hidalgo, grupos de auto ayuda (A.A, N.A) y otros grupos de estudiantes o profesionistas que vivan o hayan vivido esta situación que se reúnen en grupos parroquiales.

\section{Objetivo particular.}

1. Descubrir cuáles son los factores que permiten sostener un noviazgo destructivo.

2. Dar a conocer los hechos de esta investigación y a partir de ellos concienciar y promover el tema de noviazgos constructivos.

\section{Justificación}

Quizás sean los noviazgos violentos donde se originan las familias disfuncionales, es decir, que un noviazgo destructivo, si logra trascender al matrimonio, sin duda tendrá serios conflictos, como una familia disfuncional. El Instituto Nacional de la Mujer señala que los matrimonios conflictivos, ya lo eran desde el noviazgo, y que una mujer golpeada, es posible que antes fue maltratada psicológicamente, también en el noviazgo. Por tanto se puede pensar que gran parte de los problemas que la sociedad mexicana tiene, como la corrupción, la delincuencia, y los problemas de adicción, desviaciones sexuales, en gran medida crecen o se fortalecen en las familias con problemas.

\subsection{Estructura de la investigación}

1. El noviazgo

1.1 Noviazgo desde un aspecto sociocultural

$1.2 \mathrm{El} \mathrm{noviazgo} \mathrm{a} \mathrm{través} \mathrm{del} \mathrm{tiempo}$

1.3 Diferentes tipos y conceptos 

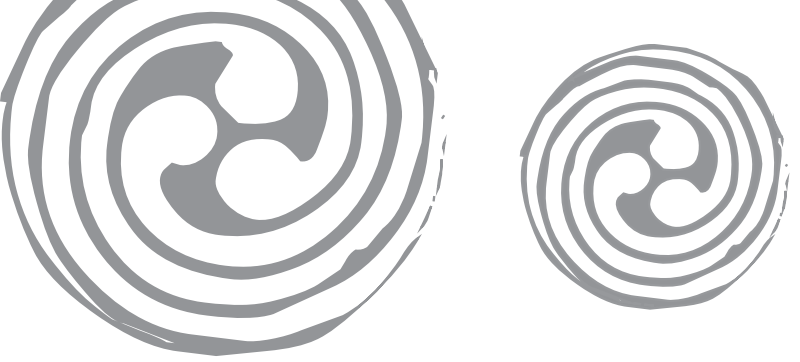

2. Noviazgos destructivos

Origen y evolución

Hechos reales

Causas

En la primera fase se abordará el tema del noviazgo desde un punto de vista sociológico y fenomenológico en la sociedad mexicana, cómo se asume, las desventajas del sexo femenino. Cabe mencionar que estas desventajas están acompañadas de ganancias secundarias, es decir, que se permite algunas situaciones que pueden parecer destructivas, por recibir a cambio, algunas situaciones de comodidad o gratificaciones, sin embargo esta realidad obedece al plano psicológico, que por tanto será tema de revisión en la continuación del texto. Pero que en el aspecto cultural se revisaran las causas que determinan llegar a una relación destructiva.

\section{Marco teórico o@}

Hablar de noviazgo no es algo novedoso, por tanto el enfoque que se quiere mostrar no pretende asumir una forma romántica, más bien, quiere mostrar el lado frío de cómo se construye una relación tormentosa.

\section{Noviazgo \\ El noviazgo desde un aspecto sociocultural}

Recurriendo a distintas fuentes, existen varias concepciones de noviazgo, sin embargo la inmensa mayoría coincide que el noviazgo es una etapa de conocimiento entre parejas y de construcción para algo. Ese algo, sin duda, es tema medular de la presente investigación, que se irá construyendo en el laberinto espiral de este trabajo.

Cuando se habla de conocerse, por supuesto se está hablando de conocer cómo es la persona que "elijo como pareja", este razonamiento, de elegir, se aborda desde factores sociológicos, que lo describen así: novio/a es aquel o aquella que «mantiene relaciones amorosas en expectativa a futuro matrimonio". (Diccionario Larousse, 1995: 204) Se trata, pues, de una situación de tránsito en las relaciones entre un hombre y una mujer antes de casarse. Situación no institucionalizada, que ha tenido a lo largo de la historia formas diversas (recuérdense los esponsales, la petición de mano), los ritos pueden ser indistintos, pero con el mismo fin, llegar al matrimonio. (Enciclopedia Aristos, 1987).

El noviazgo es una relación transitoria entre un hombre y una mujer que tienden al matrimonio. Es la relación entre dos enamorados que desean conocerse mejor para ver si llegan a casarse (Diccionario de la Real Academia Española, 1983: 239)

Esta etapa sin duda propone varios conceptos. Los que se citarán llevan a perfilar el conocimiento del noviazgo, que sin duda es la referencia teórica y práctica para observar al noviazgo. Relaciones amorosas, relaciones de enamorados y tránsito en las relaciones para llegar al matrimonio.

Hablar de relaciones de enamorados creo que es de dominio popular, por tanto sólo puntualizaré lo que es el enamoramiento desde un ámbito de igual manera, popular; "el amor es algo que no se tiene y que se quiere dar a alguien que no lo quiere" (Lacan, 1968). Ésta frase describe, lo que es el enamoramiento, pues el enamoramiento potencializa el deseo de agradar a otra persona, y exalta sus cualidades del deseado, por tanto, se dice bien, el que está enamorado vive en la fantasía, es decir, no tiene las virtudes que cree, y que, con eso piensa que atraerá a la persona "amada", pero tampoco observa objetivamente, pues lo que observa, es decir al "amado/a", "no es real, pues su cerebro ha producido demasiada oxitócina y drenalina" (Cruz, 2003) para no ver con claridad su personalidad real. Esta descripción final, no es un juicio, más bien, una circunstancia necesaria en el caminar del noviazgo.

\section{El noviazgo a través del tiempo}

Son muchos los textos que podrían hablar del noviazgo, referir a la historia del noviazgo es tan variado como antiguo, tanto, como la historia del hombre. Sin duda, no está demás la alusión al tema bíblico, que se refiere a la 
pareja que se da en la antigüedad, en el libro del génesis, Adán y Eva. Cito pues el texto que menciona a estos personajes, que sin duda son símbolos representativos de pareja universal: "No es bueno que el hombre este solo. Voy hacerle una vida adecuada" (Génesis 2, 18.) Así, parte el mandamiento divino, el irremediable acompañamiento del hombre con la mujer. Es decir desde las concepciones religiosas, que son antiquísimas, ya entonces se formulaba la relación de pareja. El hombre va en la búsqueda de su mujer. Entendiendo esta elección, como que, una de las partes buscará siempre estar acompañada en una relación amorosa con quien compartirse.

Ahora bien apenas aparece el hombre con su mujer como pareja, nos lleva al pensamiento teológico de comer del fruto prohibido, paradigma que acompaña a las parejas occidentales o judío cristianas, sin embargo no es el único hecho, pues gran parte de las culturas lo contemplan en su literatura local, los cuentos fabuloso de los griegos muestran como la mujer, es centro de conflicto de las guerras que se desarrollaron en estas culturas, Homero, en sus escritos muestra como las relaciones se vuelven tormentosas (Fermín Zumano, comunicación personal) y aunque sin duda la mujer no es centro de las culturas griegas, si, el de las pasiones de los griegos. Así sucesivamente damos cuenta como en la antigua Roma, con Cleopatra y Julio Cesar, hasta pasar los históricos, Romeo y Julieta, de Shakespeare (dominio popular), pues, sería casi imposible mencionar cómo se fraguó el primer noviazgo, pero sí cómo los tiempos muestran un ambiente tormentoso, alrededor de las parejas. Tema controversial, pues el noviazgo viene acompañado de situaciones difíciles, es parte esencial en la vida humana pero difícil de conciliar la discriminación antiquísima de la relegación de la mujer. En particular en la sociedad actual, el sexo femenino se ve amenazada por una historia trágica de machismo, viene a padecer de violencia cultural, hoy en día son muchas las campañas que han promovido la igualdad de género.

\section{Diferentes tipos y conceptos}

“...Y exclamó, jésta si es huesos de mis huesos, carne de mi carne!... por eso deja el hombre a su padre y a su madre y se une a su mujer que serán una misma carne" (Génesis 2, 23.)

Esta afirmación deberá suponer armonía, por lo menos en la concepción teológica, pues el fin de la pareja será, ser feliz, el uno al lado del otro, desde la concepción religiosa, donde esta unión servirá para la procreación. Por supuesto los rituales esponsales de los credos cristianos sugieren la castidad y el respeto a la monogamia, aún en el noviazgo. Con otras recomendaciones de tipo moral.

Otra concepción, que parte del sentido ético es la moralista, un sin fin de páginas de Internet, se refieren así del noviazgo; el noviazgo es una etapa muy bonita de la vida con la característica principal del enamoramiento, que incluye varias actitudes. Pensamiento frecuente en la persona amada, que se presenta idealizada y maravillosa. Deseo de verse, de conversar, de reunirse. Deseo de agradar a quien se ama. Sentimientos y emociones intensos ante la presencia real o imaginada del amado. Esto es lo característico del auténtico amor, mientras que los puntos anteriores son algo inestables y propios del amor-sentimiento y que se cuidan uno al otro (Goleman, 2004: 43.)

Se observa que el ámbito psicológico va encontrando mucho peso para este tema, y que tiene un punto particular de mostrar el noviazgo, por ejemplo, menciona, el noviazgo es un ritual en el que hombres y mujeres experimentan sus sentimientos amorosos hacia el otro sexo y es una oportunidad para aprender a reconocer intereses y deseos individuales. En este juego los jóvenes tratan de ensayar su identidad sexual y sus futuros roles. (Diccionario de psicología, 1990: 43) En fin, pueden correr muchas páginas de ensayos, teorías o libros clínicos que proponen una hipótesis, donde coinciden en como el noviazgo ayuda para la construcción de posibilidades, a fin de encontrar la madurez suficiente que les permitirá ser integrales y funcionales en la vida que se adopta.

\section{Noviazgos destructivos}

La palabra, destructivo, vincula automática- 

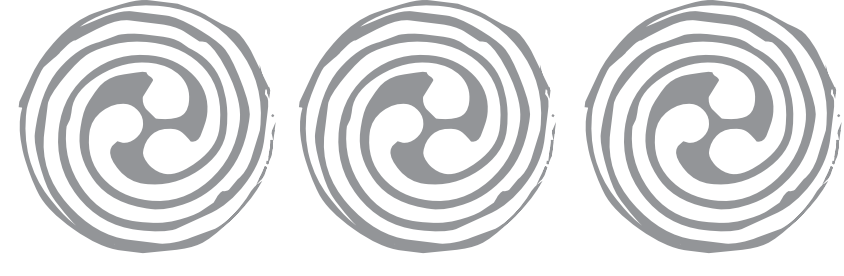

mente algo negativo, las distintas acepciones lo confirman, deshacer, arruinar o asolar, aprisionar, estropear, malgastar y malbaratar el negocio o la relación (Diccionario Larousse, 1995). Por tanto, los noviazgos destructivo se ven acompañados de una o varias acepciones que se citan, de tal manera que no den posibilidad de promover las características que observaron en el tema inicial: relaciones amorosas, o bien relaciones de enamorados y tránsito en estas relaciones para llegar al matrimonio. Por supuesto es implícito, ser feliz con él o ella, en la conciencia colectiva. Sus opuestos serían entonces, constructivos, hacer, cuidar, arreglar, apreciar, dar libertad. De tal manera que como Freud (1905) menciona que la etapa de las pulsiones de vida serán necesariamente, trascender el narcisismo primario, pues este no permite desarrollar las instancias psíquicas, estacionándose en una etapa simbiótica de ensimismamiento, que como ya lo señaló la psicoanalista Margaret Mahler (en Estrada, 1990) debe existir una etapa de individuación, así pues, la transcendencia, que consiste en depositar mis relaciones objetales en el otro, este acontecimiento se llama entonces, narcisismo secundario. Si bien se puede entender que alguien que no ha trascendido al siguiente plano, tendrá relaciones, básicamente en relación a sus necesidades, pasando por encima las necesidades de su pareja. Por supuesto esto fractura cualquier relación.

Si bien se puede pensar que existe un culpable casi demoniaco, sin embargo es importante señalar que los vínculos destructivos, no parten en forma activa del "agresor", existe la parte pasiva de la "victima", es decir, los vínculos destructivos se construyen ante la dificultad de no poder tolerar la angustia de separación, a pesar de que es normal en cualquier persona, se agudiza tanto en unas que se empieza una patología neurótica, por tanto este conflicto, si no se resuelve, es inevitable que se traslade a la pareja que será el detonante perfecto para una relación destructiva.

Finalmente puede concluirse que para lograr un noviazgo destructivo se necesitan dos responsables.

\section{Origen y evolución}

Así pues nos sirve de parámetro para reflexionar situaciones que pueden servirnos para verificar cómo se empieza el camino para llegar a un noviazgo destructivo. Las personas que tienen conductas destructivas en los noviazgos son las que te acosan, se enciman en tu ser, no permite que te desenvuelvas y desarrolles, remiden y administran tu tiempo, suprimen tu libertad, deciden si estudias o no, en fin se meten en todos tus movimientos, o los que el o ella consideren: trabajo, deporte; en casos graves, con relación a la familia verifican los movimientos que debes hacer (como salir con los padres, no estar en comidas que usualmente se estaba, principalmente la ausencia física) y amistades, otros aspectos de conductas destructivas son: aspectos violentos que ofenden o humillan a otra persona, considerando los aspectos físicos y verbales, acoso sexual, esto se da principalmente por la desventaja psicológica de alguna de las partes, existe un sin fin de mujeres principalmente en esta situación. Finalmente la situación económica es otro factor recurrente, pues el que tiene los medios económicos buscará ofrecerlos a cambio de tener control sobre la otra persona. Los hechos iniciales pueden ser tantos, pero identificar alguna situación que se ha mencionado o similar, puede dar cuenta del inicio de una situación de noviazgo difícil.

Un novio inseguro y con fragilidad yoica, al no dar libertad querrá acompañarla a todas partes sin que la persona lo prefiera, otra situación es que su cercanía con ella es únicamente para besarla y provocar intimidad para llegar además al lado sexual de la relación. El control y poder expresado a través del uso del celular a todas horas será un recurso para una persona destructiva, en fin, sólo provoca situaciones violentas para la víctima.

Si bien puede ser subjetiva la intensidad o recurrencia de los hechos, nos llevará a observar la realización y construcción de un noviazgo destructivo o los hechos que ocurren para llegar ahí, por supuesto permitirá un parámetro de conocimiento concreto de actitudes para un noviazgo tal. 


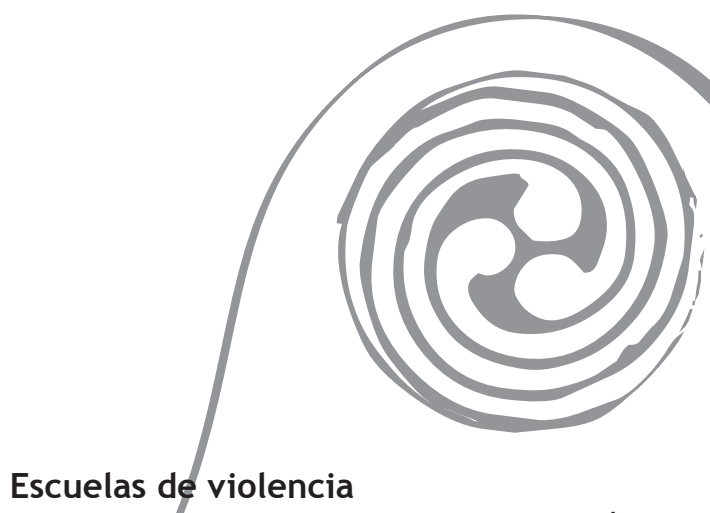

Salvador quenta que su padre le enseñó a beber alcohol glando cumplió 14 años. Desde entonces, cada Navidad toma con sus familiares hasta el amanecer, mientras las mujeres preparan las botanas, compran las cervezas cuando se acaban y limpian la casa.

"Así debe ser, sino, ¿cómo?" Menciona.

El ejercicio de prácticas agresivas se aprende. Ximena comenta que cuando Salvador la golpeó por primera vez su familia intentó obligarla a denunciarlo, pero ella se negó justificando esa conducta con los problemas familiares que él tenía: "yo les dije que no lo entendían, él es así porque tiene problemas en su casa y si lo quiero debo entenderlo".

Pero no son los hombres los únicos que ejercen violencia en las relaciones. Las mujeres comúnmente recurren a chantajes cuando ven amenazada la permanencia de su pareja. En la mayoría de los casos exponen su seguridad personal para generar remordimiento, o condicionan las relaciones sexuales.

Los resultados de la violencia en el noviazgo: depresión, bajo rendimiento escolar, embarazos no deseados, enfermedades de transmisión sexual, intentos de suicidio y, lo esencial, la reproducción de la violencia.

De acuerdo con el estudio Hombre, violencia y crisis social. Curso sobre masculinidad, realizado en 1995 por el Centro de Educación y Comunicación Popular, en Managua, Nicaragua, la violencia es un aprendizaje y, por tanto, se desaprende. Si la causa central que genera violencia es la construcción social bajo la cual vivimos, entonces debemos cambiarla. Por ello, uno de los principales objetivos de los programas sociales es "desacostumbrar los ojos sociales a ver conductas que son considerados normales para reconocer cuándo somos víctimas de agresiones y así poder identificar cuándo una relación es violenta. Es decir, debemos enfocarnos a cambiar las relaciones sociales desde la interpretación que cada hombre y mujer tiene sobre su papel como parte de un conjunto".
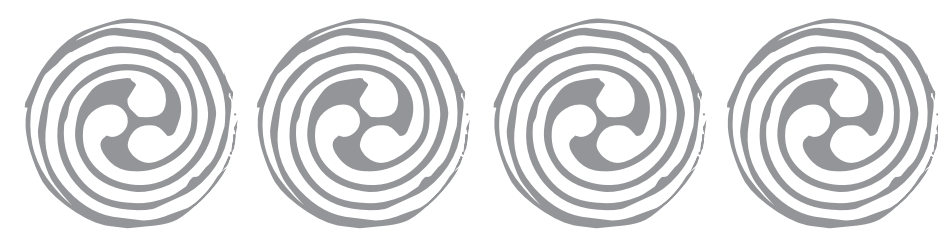

Hace tres semanas, Ximena terminó con Salvador. "Ya no quiero que sepa nada de mi vida, lo mejor es dejar las cosas en paz", comenta. Pero desafortunadamente, señala Terrazas, la mayoría de los jóvenes padecen situaciones similares en sus relaciones de pareja, a falta de programas específicos para combatir la agresión en el noviazgo adolescente.

\section{Causas}

No se si se pueda contestar objetivamente, pero la respuesta puede iniciarse desde un panorama social; sin embargo, no es suficiente para considerar que sea el motivo principal, la permisivilidad de este acontecimiento, socialmente tiene mucho que ver, sin duda el texto narra varios episodios donde la mujer asume ese rol. La sociedad permite estos hechos. Por supuesto no son los únicos factores, habrá otros que quizás se mencionen en esta investigación o que ya se tocaron, sin embargo al ser un factor humano, pueden quedar olvidados o sin darle relevancia. Pero al pretender ser una investigación de psicología que dé respuestas, a estos hechos sociales, debe señalar los presupuestos psicológicos.

Por tanto surge en la inmediatez la confrontación emocional, por un lado la conveniencia cognitiva del hombre, sobre la, que parecería, infortunada emocionalidad de la mujer, se menciona inconveniencia, porque al estar atrapada en las redes semánticas de los significados emocionales, no se permite observar por encima de lo que siente, qué le conviene, Así pues el bajo nivel de inteligencia emocional (Goleman, 1995) que dejará en desventaja para el equitativo juego del noviazgo. Los conflictos se acumulan en una relación inferior, claro, desde el lado emocional, desde la evidencia que se ha revelado, es decir, "Me significa y me construye más, lo que siento, que lo que creo". Los conflictos en la pareja se pueden agrupar alrededor de los aspectos fundamentales que estructuran la pareja y que se han planteado hasta aquí:

Intimidad. Epstein, Baucom, Tankin y Burnett (1991) identifican como áreas de conflicto, la propia existencia de una relación de dominio en la pareja se ha mencionado como causa de 
conflictos y de injusticia, sobre todo desde el punto de la teoría de unas relaciones equitativas; pero no se ha demostrado empíricamente que sea así (Gottman, 1998). Puede darse el dominio sin que aparezca o se perciba ninguna distorsión. Además la toma de decisiones tiene la característica de ser una habilidad escasa y difícil y por ello un bien preciado. El apoyo que cada uno obtiene de la pareja en la toma de decisiones individuales o conjuntas, puede ser uno de los refuerzos básicos que se obtiene de la relación. Por ello aunque exista una relación de dominio de un miembro sobre el otro puede ser considerada como algo aceptable e incluso deseable porque evita la tarea desagradable de tomar decisiones.

Problemas en la comunicación, la fundamentación de la comunicación va implícita, y resolución de problemas. Una vez que aparece un conflicto en cualquier área se disparan en la pareja los mecanismos para resolverlo. Las habilidades de comunicación, de resolución de problemas, la estructura de poder, se ponen en marcha para solucionarlo. Si no consiguen hacerlo, se establecen en la pareja patrones de relación que lo perpetúan o incluso lo agravan. Cuando el tiempo pasa sin hallar solución, o los problemas se multiplican, el origen de las dificultades se olvida y llega a parecer que no existen elementos desencadenantes de la situación y que es la propia convivencia la que se convierte en problemática.

Si bien existen otras alternativas para consultar este fenómeno, una que es viable por su discurso existencialista, además pretendiendo que esta investigación tenga esta vertiente, sobre la teoría de Soren Kierkegaard (1843), en su obra relata cómo se dan los fenómenos para "atrapar al la persona deseada, y salir bien librado", sin duda su obra más representativa que menciona la indiscriminada variedad de lenguajes, artimañas para seducir a la mujer, y después sin duda, dejarla. Estará en juego lo ético o lo estético o el compromiso o el placer, que quizá no sean compatibles, dice el autor. Esta obra refleja cómo el hombre se goza de obtener a la mujer que desea, sin ninguna ética y una vez en sus manos desechar la relación, pues ya ha perdido todo su encanto, creo que esto sucede cuando en la pareja se ha enfocado a relaciones genitales por encima de la construcción emocional, o por lo menos así lo enfoca la perspectiva Kiekergaardiana. Aquí ya está construido el desarrollo del goce, te tengo, apropiación que descubrió el hombre; te aprovecharé, pues tú no tendrás comunicación para reclamarlo; tu intimidad me pertenece, pues aquí quizá, solo quizá ya fuiste mía.

\section{Ganancias secundarias/}

\section{Pérdida de la identidad}

El lenguaje psicoanalítico de la histeria, (Freud, 1910) menciona que la mujer provocará el panorama de conflicto para obtener ganancias secundarias, dicho de una forma coloquial, inicia una pelea en la cual perderá con facilidad, y después será la "mártir". Esta situación tiene consigo una dosis importante de goce, (Braunstein, 1990) se tiene que hacer la diferencia entre goce y placer, uno, el primero tiene por complejidad compromiso, tanto de disfrutar como de hacer disfrutar, y una vez acontecido llega a su fin, por el contrario del goce, que se vierte en la individualidad y no se fija en el disfrute del otro, pareciera, menciona Braunstein, que no tiene fin, una especie de levedad, donde todo es igual, no hay principio ni éxtasis, por tanto si no hay principio, no puede haber fin, y si no tiene fin, en el disfrute no causa relevancia, hay costumbre, no hay motivación, solo eso, levedad; así pues, el noviazgo del goce, augura ya de inicio, el egoísmo. Quien sabe cuánto, y en forma de hipótesis para otra investigación, comentar al lado de un hombre agresivo, casi siempre habrá una mujer que busque estar ahí, parece que lo disfruta. Esto es similar a la teoría del goce de Braunstein. Por supuesto, esta muestra de poca inteligencia emocional se verá impactada desde ámbitos destructivos, que es cierto, se pueden tener puentes de construcción al mo delaje de noviazgos constructivos.

Finalmente, existe mucho material que habla del amor, o de los problemas existenciales entre el hombre y la mujer, es importante reconocer que, en estos hechos va implícita y silenciosa la amenaza de los problemas destructivos, este 
ejercicio posibilita tener parámetros objetivos y opciones que permitan trascender la situación actual de personas instaladas en la realidad de los noviazgos destructivos por modelajes constructivos.

"La lectura correcta de los viaductos internos de mis emociones, son la expresión madura de mis actos" (comentario personal).

Sin duda el comentario final abarca la más sincera opinión de cómo el descuido de las emociones, permitirán entrar en juegos que no se sabe jugar y que además jamás se hubiese pensado entrar siquiera.

\section{Metodología o@}

\section{Enfoque de la investigación}

Enfoque cualitativo

Etnometodología:

La tarea de recolección de datos fue a través de dos instrumentos, que se anexan al final (Historia de vida y entrevista semiestructurada), el desarrollo con el entrevistado fue únicamente para realizar la entrevista y de ninguna manera se tendrá en cuenta el proceso de noviazgo o pareja que ellos sigan.

\begin{abstract}
Alcances
Los alcances serán de forma descriptiva; la razón es porque se pretende describir los procesos fenomenológicos de causalidad destructiva que desarrollan algunas parejas de novios, y como lo explican ellos mismos de su experiencia en una lógica, que será en forma comentada.
\end{abstract}

\section{Hipótesis}

Los vínculos destructivos se construyen ante la dificultad de no poder tolerar la angustia de separación, normal en toda relación de pareja.

Variables

Independiente

Violencia

Definición conceptual:

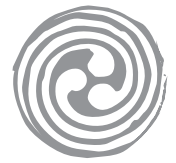

Modo de proceder en contra de la naturaleza, forzar, violar a una mujer, irrumpir, profanar algo sagrado, destruir alguna resistencia, impetuosamente, entrar sin aviso (Diccionario de la lengua española, 1986) son mediacjones que comprenden la violencia.

Definición operacional:

En esta investigación, el noviazgo destructivo se definirá como: una relación de pareja de hombre y mujer que violentan, uno al otro, no permiten la separación, no se desarrollan, administran mal su tiempo, suprimen su libertad, no permiten su individuación separación, ejerciendo violencia a nivel físico, verbal y emocionalmente.

\section{Dependiente}

Destructivo

Definición conceptual:

La palabra, destructivo, vincula automáticamente algo negativo, las distintas acepciones lo confirman, deshacer, arruinar o asolar, aprisio nar, estropear, malgastar y malbaratar el negocio o la relación (Diccionario Larousse, 1995).

Definición operacional:

En mi investigación el noviazgo destructivo se definirá como una relación de pareja de hombre y mujer que acosan, no permiten que se desenvuelvan y desarrollen, administran el tiempo, suprimen la libertad, deciden gran parte de los movimientos, como estudiar, trabajar, qué hacer desde ir al cine o hasta tener relaciones intimas, aun si está o no de acuerdo la otra parte, es decir ejercer violencia en tres sentidos; física, verbal o psicológica.

\section{Unidad de análisis \\ Población}

Jóvenes de la ciudad de Pachuca, de la Universidad La Salle, de La Universidad Autónoma del Estado de Hidalgo, grupos de auto ayuda (A.A, D.A) y un grupo de profesionistas que se reúnen en un grupo parroquial y en un club nocturno elegido al azar. Las edades oscilan entre los 20 y 30 años de edad. 


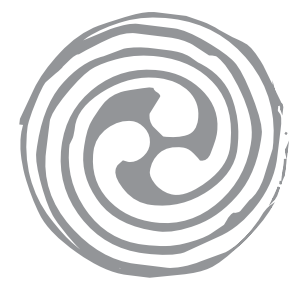

Muestra análisis

No probabilística.

La muestra se obtuvo de personas conocidas que es de dominio común que mantienen un noviazgo destructivo, la invitación a la entrevista fue de forma personal, y los espacios que se eligieron fueron; dos distintos bares de la ciudad de Pachuca, La Universidad La Salle, La Universidad Autónoma del Estado de Hidalgo y la Universidad del Fútbol, Profesionistas que participan en Grupos de ayuda, Alcohólicos Anónimos y Adictos Anónimos.

\section{Diseño de la investigación}

Cuasi experimento:

Se piensa en este diseño por la razón que existen ya situaciones determinadas. $Y$ aunque no hay variables se determina que si se observa a través de su misma narración un fenómeno de cambio, de tal manera que se considera fenomenológico en relación a lo que ya aconteció, ya se investigó, y solo el presente trabajo se avoca a las referencias ya establecidas en relación al tema.

\section{Instrumentos}

Se anexa al final

\section{Análisis parcial de datos}

El análisis es cualitativo, por tanto la explicación corresponde, únicamente a los comentarios de las 10 entrevistas que se realizaron. Los datos que se obtuvieron fueron los siguientes: de las diez entrevistas coinciden en que hubo palabras violentas, además en 7 hubo algún tipo de violencia física, en 5 de estas entrevistas existió infidelidad por parte de la mujer. Todos los personajes coinciden que sabían que algo marchaba mal, pero no supieron o no quisieron hacer algo, de los 10, sólo dos intentaron hablar, pero no tuvieron acuerdo, otros dos cuando peleaban, su reconciliación era a través de tener relaciones sexuales.

\section{Interpretación de los datos}

Se codificaron las causas de mayor trascendencia: Lenguaje violento: cabrona, puta, pendeja, pinché loca; gritos: Presión psicológica; celos: hacer cosas en desacuerdo, chantaje,

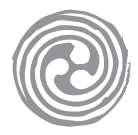

como preguntas ies que ya no me quieres? 0 amenazas; si no me acompañas no habrá sexo, otro aspecto de/presión es ya no eres virgen por tanto solo conmigo tendrás que estar, o ya no vales la pena pues ya te acostaste conmigo, Sexo; sin común acuerdo, a fuerza, Vicios, alcoholismo, drogadicción. Económicos, por interés (estar con la persona por obtener remuneración económica) o por estatus social, es decir que se rá novio por sueconomía, y no por aprecio a la persona en sí. Baja autoestima, esta situación abarca varios aspectos que se mencionan en algunas situaciones anteriores, pero uno a resaltar, es sin duda el poco aprecio que se tiene de sí mismo, como usar adjetivos descalificativos para sí mismo. Infidelidad, la palabra explica la situación, pero lo que quiero resaltar es que la infidelidad de las diez entrevistas en 5 fueron iniciadas por la mujer.

\section{Resultados 0@}

Los resultados que se obtuvieron son lo siguientes, en todo noviazgo destructivo existen problemas de comunicación, cuando empieza a molestar alguna de las partes de la relación no hay la confianza para comentarlo y prefieren guardar silencio esperando que el otro/a sea quien rectifique por sí mismo, el guardar silencio obedece a algo cultural, pues la solución de problemas a través del diálogo no es algo muy frecuente, otro factor trascendente es que no pusieron límites en alguna de las partes, en el primer intento de violencia, se realizó una omisión, sin duda las groserías son un parámetro fundamental para considerar que la relación es destructiva. Los datos que se interpretaron sugieren comentar que otro fuerte impacto en la destructividad de la pareja son las caricias precoses y el sexo forzado, es decir que existe un fuerte vínculo en la agresión y el sexo prematuro, esta consideración se explica como un fenómeno de limitación en relación a la pareja. Las caricias recurrentes son la ante sala a esta situación meramente egoísta. 


\section{Conclusiones}

Los objetivos planteados fueron cubiertos en parte, se logra visualizar algunas características que permiten dar un juicio, para interpretar si alguna relación es o no destructiva, también la experiencia obtenida sin duda manifiesta las tendencias de los noviazgos, los objetivos particulares se resuelven en la medida que se dé a conocer estos hechos actuales en muchos novios. Si bien, en el desarrollo de este tema, en el marco teórico, se señala la profundidad del tema, pues es un aspecto que la historia misma señala como trascendente, no por demás se escribe del noviazgo por todos lados, recalco que los resultados pueden prevenir algún posible romance que sea destructivo para en todo caso corregir o bien claudicar antes de que sobrevivan y se casen teniendo una familia disfuncional que perjudique por supuesto a la sociedad, sin duda prevenir un noviazgo destructivo puede prevenir una familia disfuncional, y con esto un posible problema social.

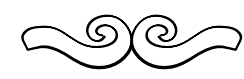

\section{Fuentes de Consulta}

BRANDEN Nathaniel (1986), Seis pilares de la autoestima, México; Editorial Paidós

BRAUNSTEN Néstor (2005), Goce, Argentina; Editorial, Siglo XXI

Centro de Educación y Comunicación Popular (1995), "Hombre, violencia y crisis social. Curso sobre masculinidad”, en La violencia es un aprendizaje, Managua, Nicaragua,

Diccionario Larousse de la Real Academia Española (1987), Editorial Larousse

Diccionario de psicología (1998), Editorial Origen Planeta.

ESTRADA India Lauro (1990), Para entender el amor, México; Grijalbo

FREUD Sigmund (1905), Obras completas capítulos 7, 14 y 24, Argentina; Amorrortu Editores

GOLEMAN Daniel (1998), Inteligencia emocional, EE.UU.; Editorial Vergara

KIERKEGAARD Soren (1878), Diario de un seductor, Dinamarca; Editorial Océano.
LEMARE Jean G. (1979), La pareja humana: su vida su muerte y su estructura,

Francia; Fondo de Cultura Económica

PAPALIA Diane E. , Desarrollo humano, EE.UU. Editorial; Mc Graw Hill

RODRÍGUEZ Nallely, "Testimonio; Agredidas durante el noviazgo", La jornada/ agencia notice, Martes 7 de marzo del 2006

\section{Anexo.}

Instrumento 1:

Entrevista semiestructurada

Nombre

Edad

Profesión o estudios

1. Regularmente peleas en tu noviazgo

2. Identificas las causas

3. Accedes a situaciones que te propone tu novio/a y luego te sientes mal

4. Te sientes presionado/a por alguna situación con tu novio/a

5. Ha habido golpes en tu noviazgo

6. Ha habido algún tipo de violencia física, verbal o psicológica

7. Puedes mencionar cómo son las relaciones sexuales que practican

8. Causas por las que aceptas el maltrato

Instrumento 2:

Historia de vida

Nombre

Edad

Profesión o estudios

Platica la experiencia que has tenido a lo largo de tu vida en tus noviazgos:

Actualmente cómo es la experiencia que llevas con tu novio: 